\title{
LA EXPORTACIÓN DE COMPONENTES HUMANOS EN EL DERECHO LATINOAMERICANO*
}

\section{Gustavo Adolfo García Arango**}

Fecha de recibido: 18 de abril de 2014.

Fecha de aprobado: 8 de agosto de 2014.

Artículo de revisión

Forma de citación: García, G. (2014). La exportación de componentes humanos en el derecho latinoamericano. Revista Prolegómenos. Derechos y Valores, 17, 34, 146-161.

\section{Resumen}

Este artículo presenta un trabajo de revisión jurídica sobre la normatividad relacionada con la exportación de órganos y tejidos humanos en varios países latinoamericanos, en tres bloques complementarios: primero, se hace un estudio general de algunos aspectos de la industria del trasplante de órganos; segundo, se realiza un comentario sobre la visión antropológica del comercio del cuerpo humano; y tercero, se exponen los resultados del rastreo jurídico a México, Guatemala, Honduras, El Salvador, Colombia, Bolivia, Chile, Costa Rica, Perú y Argentina respecto al tema en análisis.

\section{Palabras clave:}

Donación de órganos, exportación de órganos, industria del trasplante.

\section{EXPORT OF HUMAN ORGANS IN LATIN AMERICAN LAW}

\begin{abstract}
This article submits a work of legal revision about regulations related to the export of human organs and tissues in several Latin American countries, in three complementary blocks: first, a general study of some aspects of organ transplant industry; second, a remark about the anthropological vision on the human body trading; and third, the results of the legal tracking on Mexico, Guatemala, Honduras, El Salvador, Colombia, Bolivia, Chile, Costa Rica, Peru and Argentina regarding this subject.
\end{abstract}

\section{Key words:}

Organ donation, organ export, transplant industry.

Artículo producto de la investigación "Algunas implicaciones jurídicas del comercio de componentes humanos en Colombia y otros países latinoamericanos". Terminada y aprobada. El autor del artículo fue el investigador principal. Investigación inscrita en el Grupo de Investigaciones Jurídicas de la Universidad Católica de Oriente.

** Filósofo de la Universidad Pontificia Bolivariana (UPB); abogado de la Universidad de Antioquia; especialista en Derecho Privado y magíster en Derecho de la UPB. Abogado del Municipio de Medellín, docente Universidad de Antioquia e investigador del Grupo de Investigaciones Jurídicas de la Universidad Católica de Oriente. Correo electrónico: garcia.arango@yahoo.com 


\title{
A EXPORTAÇÃO DE COMPONENTES HUMANOS NO DIREITO LATINO-AMERICANO
}

\begin{abstract}
Resumo
Este artigo apresenta um trabalho de revisão jurídica sobre a normatividade relacionada com a exportação de órgãos e tecidos humanos em vários países latino-americanos, em três blocos complementários: primeiro, se faz um estudo geral de alguns aspectos da indústria do transplante de órgãos; segundo, se realiza um comentário sobre a visão antropológica do comercio do corpo humano; e terceiro, se expõem os resultados do rastreio jurídico a México, Guatemala, Honduras, El Salvador, Colômbia, Bolívia, Chile, Costa Rica, Peru e Argentina respeito ao tema no analise.
\end{abstract}

\section{Palavras chave:}

Doação de órgãos, exportação de órgãos, indústria do transplante.

\section{INTRODUCCIÓN}

La medicina avanza a grandes pasos, también la población del mundo y la globalización de la economía, lo que genera varios impactos en el mercado de la salud, en donde se mueven millones de dólares tanto por el costo de la formación y salarios de los profesionales, como por la compraventa de insumos médicos y sanitarios (jeringas, gasas, algodón, agujas, hilos quirúrgicos, etc.), tecnología y medicinas que se comercializan entre los países gracias a las empresas multinacionales, a los grandes distribuidores o a las conexiones internacionales vía Internet, como páginas web, correos electrónicos o telemedicina.

Un segmento que tiene bastantes años en la historia de la medicina (Gracia, 1996; LópezNavidad, Kulisevsky \& Caballero, 1997; Sodi, 2003) y que es interesante para el mercado es el de los trasplantes, por la escasez de las donaciones y los problemas de compatibilidad entre donante y receptor. Aunque los avances científicos en sí mismos son importantes, las miradas no se enfocan solo en la intervención "cuanto en los aspectos personales y sociales que acompañan los trasplantes" (Sánchez, 2005, p. 345). Por miles se cuentan en cada país las personas en listas de espera de un riñón, un hígado, un pulmón o un corazón; en muchas ocasiones los órganos son de vital urgencia y en otros, las personas pueden esperar por años hasta que les llegue el donante que requieren. Esta situación ha creado un mercado interno mucho más fuerte alrededor de los trasplantes, que promueve tanto mercados legales como ilegales a la hora de obtener un trasplante de órgano. Pero la situación presenta una circunstancia social, económica, ética y jurídica particular, cuando se habla de exportación de componentes humanos, es decir, del envío de órganos -por ejemplo- de una nación, donde puede o no haber necesidades internas, a otro, $y$ donde el derecho ha entrado a operar por la misma necesidad que la sociedad le ha presentado, porque "aunque, a veces, se diga que el derecho configura las relaciones sociales, esto no es así, son estas y no él las que determinan el nacimiento de una nueva legislación" (Díaz-Ambrona, Serrano, Fuertes \& Hernández, 2007, p. 61).

En la investigación general, de donde deriva este artículo, se buscó determinar el impacto del comercio de componentes humanos en el derecho privado. Y para ello, el primer estudio consistió en identificar cómo se regulaba jurídicamente en varios países latinoamericanos la salida al exterior de componentes humanos, ya que se convierte en un problema dados los siguientes factores, algunos ya mencionados: primero, escasean; segundo, el comercio de componentes 
humanos se encuentra prohibido jurídicamente en la gran mayoría de países; tercero, por principio de distribución, se debería atender la demanda interna antes que la de otros naciones; cuarto, el turismo de órganos puede verse beneficiado; quinto, los centros autorizados para trasplantes podrían aprovechar la posibilidad de la exportación para comerciar con ellos.

Con este marco se desarrolla la investigación desde un enfoque cualitativo, con uso del método documental y el derecho comparado en veinte países de la región ${ }^{1}$, para rastrear las normas que se vinculan con el tema, encontrándose información relevante en México, Guatemala, Honduras, El Salvador, Costa Rica, Cuba, Colombia, Bolivia, Chile, Perú y Argentina.

Con el método documental se trató de ubicar la normatividad en las páginas oficiales de cada país, situación que fue difícil en algunos casos. Se tuvo como documento guía de control, el texto Legislación sobre donación y trasplante de órganos, tejidos y células: compilación y análisis comparado de la Organización Panamericana de la Salud (2013). Aunque este documento es del año 2011 para el 2013, ya varias normas en el continente habían sido modificadas en los años 2012 y 2013, como el mismo documento lo pronostica.

\section{LA INDUSTRIA DEL TRASPLANTE}

El comercio de órganos no solo mueve la economía ilegal, sino además muchos otros aspectos comerciales que son lícitos y aportan a todo el mercado común que está alrededor de los órganos humanos.

El Ministerio de la Protección Social colombiano en concepto 2065/2004, haciendo énfasis en la donación de sangre sin ánimo de lucro, expresa que la sangre no se puede comercializar y por

Se revisó la normatividad de México, Guatemala, Honduras, El Salvador, Nicaragua, Costa Rica, Panamá, Cuba, República Dominicana, Puerto Rico, Venezuela, Colombia, Ecuador, Perú, Brasil, Bolivia, Paraguay, Chile, Uruguay y Argentina. ende no se sujeta a una valoración económica, pero "lo anterior no es impedimento para que puedan facturar los costos correspondientes a reactivos $e$ insumos y otros costos inherentes al proceso, como es caso de conservación, transporte, extracción, etc., en aras de recuperar dicha inversión".

En otro concepto del Ministerio de la Protección Social, 3763/2005, vuelve y se pronuncia sobre los aspectos que pueden ser cobrados por las Unidades de Biomedicina Reproductiva, que "podrán cobrar los costos ocasionados por la consulta, procedimiento quirúrgico, laboratorio, extracción, preservación, las pruebas o exámenes requeridos previamente para la donación o la implantación del componente anatómico, entre otros, inherentes a la prestación del servicio".

Si bien el órgano como tal no puede comprarse ni venderse (García, 2012), ni hacerse publicidad relacionada con ello (García, 2011), ni turismo de órganos (Baquero \& Alberú, 2011), ni empresas dedicadas a su extracción, ni los bancos de componentes humanos pueden tener ánimo de lucro; tampoco puede afirmarse que no exista un mercado lícito-como espacio de intercambio de bienes y servicios, incluyendo el dinero como bien- ni negarse que hay una economía alrededor de los componentes humanos basada en múltiples productos, diversos servicios, precios, clases de consumidores, formas de pago, tipos de distribución, salarios y demás, que terminan por impactar la economía nacional de los países, en su producto interno bruto, inflación y demás datos macroeconómicos. "Si bien, el receptor no debe pagar por el órgano que necesita, como lo expresa la misma ley, sí debería pagar los costos que implica la sustracción de un órgano" (Guerra \& Márquez, 2011, p. 52).

Algunos de esos elementos de mercado que se manejan dentro de la economía legal de los componentes humanos son los siguientes:

- El pago de profesionales y personal técnico: todo el proceso del trasplante de órganos, tejidos y células exige de un personal con 
entrenamiento en todos los niveles, como médicos generales y especializados, enfermeras, paramédicos, pediatras, microbiólogos, psicólogos, entre otros (Brena, 2002). Desde el galeno que hace la consulta general, el personal comprometido en la extracción del componente humano, los que se encargan de hacer las pruebas de laboratorio, el equipo involucrado en el transporte del componente, hasta los sujetos incluidos en el trasplante, todos ellos representan dinero a través de salarios $\mathrm{u}$ honorarios que sí les produce un lucro y que impactan la economía en la capacidad de compra de este personal y en el nivel de desempleo.

- Costos de mantenimiento de los componentes humanos: para este caso, por ejemplo, el decreto supremo 24671 que reglamenta la Ley de Donación y Trasplante de Órganos, Células y Tejidos de Bolivia, determina que "Los costos emergentes de mantenimiento de órganos, células y tejidos procedentes de personas con muerte cerebral para trasplante, debidamente autorizados, correrán por cuenta de el o los receptores" (art. 25).

- Clínicas, centros hospitalarios, laboratorios y bancos: las mismas normas y conceptos colombianos, aunque prohíben el pago por el órgano, son enfáticas en señalar que el costo del trasplante sí se cobra, con el fin "de recuperar dicha inversión", y es obvio porque nadie trabaja a pérdida, de este modo serían inviables las instituciones prestadoras de estos servicios. Sin embargo, tampoco laboran por el valor exacto del costo de la prestación del servicio, sino que perciben el dinero en porcentajes más altos que este, por lo que si bien no generan utilidades que serán distribuibles entre socios, sí provocan un excedente a la entidad, generándole dividendos.

- Equipos médicos: en el mercado nacional e internacional, existen múltiples empresas de todos los tamaños que se dedican al desarrollo de la tecnología médica y a la fabricación de toda la maquinaria e instrumentación requerida para este tipo de procesos (Brena, 2002). La cadena comercial para equipos de trasplantes inicia con las investigaciones, continúa con los productores y desemboca en las empresas que se ocupan de la venta y distribución de todos los implementos, instrumentos, equipos y maquinaria necesaria, y hasta podría decirse que incluye el beneficio económico que le representa a las instituciones médicas, la prestación del servicio que se realiza con los equipos y la maquinaria adquirida.

- Empresas farmacéuticas: no solo las entidades donde se presta el servicio de extracción y trasplante ni las empresas productoras de instrumentación, equipos y maquinaria de alta tecnología se favorecen de los trasplantes. Gran parte de la posibilidad de realizar todo tipo de trasplantes en el mundo se debe al desarrollo de medicinas que permiten controlar infecciones, reacciones alérgicas, pero sobre todo, previenen el rechazo del órgano o tejido trasplantado, que era el mayor problema a la hora de efectuar un trasplante. Un solo fármaco puede generar miles de millones de dólares en ventas para una compañía multinacional y "Según algunas estimaciones, el sector farmacéutico crecerá en los mercados emergentes, entre los que se incluye México, entre $14 \%$ y 15 \%" (Torres \& Gutiérrez, 2009, p. 2).

- Agencias de viajes, aerolíneas y hoteles: todo esto es denominado turismo de salud (Baquero \& Alberú, 2011), que incluye -en clúster o de manera independiente- los servicios que se prestan a través de clínicas, agencias de viajes, hoteles, firmas de transporte aéreo y terrestre, restaurantes, entre otros, a todos los extranjeros que viajan de un país a otro o de una región a otra de la misma nación con fines sanitarios. Esto es completamente legal y mueve varios millones de dólares al año.

- Pago de recompensas: en México, la falta de donantes de órganos llevó a la Fundación Nacional de Trasplantes (Funat), al Grupo 
Carso y a la Fundación ALE, a diseñar un plan de promoción que consiste en la creación de un fondo para pagarle incentivos a médicos y enfermeras por cada órgano o tejido que consigan para donarlos a quienes necesitan de un trasplante: "¿Incentivos para la donación de órganos? Existen algunas experiencias, pero esto aumenta el costo final de cada trasplante, puede generar diferencias entre diversos sectores de la población" (Manterola, 1997, p. 185).

Los órganos deben ser obtenidos de personas con muerte cerebral. "Esta es la primera vez que organizaciones civiles ofrecen recompensas económicas para promover la 'cultura de la donación de órganos' en nuestro país" (El Universal, 22 de enero 2009, p. 2). Frente a esto, se lee la siguiente crítica:

Los espectaculares resultados de la Organización Nacional de Trasplantes se consiguen "mediante fuertes estímulos financieros que en otras naciones no se aplican": el coordinador de trasplantes, los médicos y las enfermeras dedicados a esta actividad cobran mucho más que otros trabajadores sanitarios, gracias a incentivos monetarios a la producción (no a la calidad ni a la eficiencia) que hacen que se esfuercen más para conseguir posibles donantes y órganos. Los expertos en trasplantes se quedan el dinero en lugar de los donantes o sus familiares, quienes no reciben ninguna compensación. Y mientras tanto, los pacientes con otros problemas no reciben un tratamiento tan exquisito (Capella, 2001, p. 1).

- Pago de seguros: en la industria del trasplante, las empresas aseguradoras desempeñan un papel significativo en la sostenibilidad del sistema a través del pago de seguros de vida de los pacientes, pero sobre todo, mediante los seguros de responsabilidad civil que tienen las instituciones encargadas y los médicos en particular. La responsabilidad por daños ocasionados en los trasplantes puede imputarse por órganos defectuosos a los que se les hizo un tratamiento inadecuado $\mathrm{u}$ órganos ya pasados de tiempo; por lesiones colaterales a la extracción del órgano o en el trasplante; por infecciones producidas en la cirugía o por daños originados con la anestesia. Existen seguros específicamente en caso de trasplantes, los cuales cubren hasta por un monto determinado, gastos de clínica, anestesista, cirujano, transporte, etc.

Como puede verse, los trasplantes, sin contar el comercio ilegal, generan un millonario comercio alrededor del mundo, en donde se benefician tanto personas particulares como personas jurídicas, con ánimo y sin ánimo de lucro. Y es que, en general, las normas de todos los países aunque prohíben el lucro por los órganos, permiten el cobro y el pago de los gastos en los que se incurre desde la hora de extraer el órgano hasta la posoperación de trasplante. Pero no todas las personas tienen los recursos para acceder a estos servicios, y ello suscita el interrogante sobre "¿cómo habrían de asignarse los recursos sanitarios? Aunque la anterior es una pregunta de tintes políticos, la distribución de los recursos limitados es en sí una cuestión política que repercute directamente en la atención del paciente" (Cantú-Quintanilla, 2010, p. 157).

La Organización Mundial de la Salud (OMS), por ejemplo, dentro de los principios que deben regir los trasplantes, expresa en el principio $5^{\circ}$ :

La prohibición de vender o comprar células, tejidos y órganos no impide reembolsar los gastos razonables y verificables en que pudiera incurrir el donante, tales como la pérdida de ingresos o el pago de los costos de obtención, procesamiento, conservación y suministro de células, tejidos u órganos para trasplante (OMS, 2010, p. 5).

También, la ley 296 del 25 de diciembre de 2002 , denominada "Ley de Donaciones Anatómicas de Puerto Rico" (enmendada por las leyes 26/2011, 85/2012 y 210/2012) establece en el artículo 9:

Compensación. Las donaciones de la totalidad o parte del cuerpo o de órganos para trasplante 
vivo no serán objeto de compensación o remuneración de clase alguna. No se entenderá como violación de esta sección el que el donatario u otra persona pague los gastos realmente incurridos en la donación.

De igual manera, Venezuela contempla la misma disposición, luego de prohibir cualquier retribución o compensación en la Ley sobre Trasplante de Órganos de Venezuela:

No estarán comprendidos dentro de esta prohibición la retribución que las instituciones y los bancos de órganos o materiales anatómicos, puedan recibir por concepto de transporte y conservación de los órganos o materiales anatómicos que suministren, así como los honorarios del personal que intervenga en el acto de retiro o trasplante (art. 7).

En la misma dirección, el inciso segundo del artículo $3^{\circ}$ de la ley chilena 19.451 , del 29 de marzo de 1996 y modificada por la ley 20.413 del 15 de enero de 2010, dispone que

Los gastos en que se incurra con motivo de la extracción del órgano que se dona, forman parte de los gastos propios del trasplante y serán imputables al sistema de salud del receptor de acuerdo [con] las normas legales, reglamentarias y contractuales que correspondan.

Argentina posee una normatividad administrativa algo más amplia a través del decreto 512/1995, que reglamenta la ley 24.193 de 1993 de trasplante de órganos y material anatómico humano (modificada por ley 26.066 de 2005); establece en el artículo 16 que se "entiende que la liberación de gastos vinculados con la intervención quirúrgica, comprende exclusivamente aquellos relacionados directa o indirectamente con el acto médico de ablación, implante y posoperatorio tanto del receptor como del dador vivo". Y a continuación, estipula que la Secretaría de Salud del Ministerio de Salud y Acción Social, previo informe del Instituto Nacional Central Único Coordinador de Ablación e Implante, es quien se encarga de fijar el valor de obtener órganos y tejidos por: diagnóstico de muerte del potencial donante, mantenimiento biológico del donante hasta la extracción del órgano o material anatómico, los estudios de histocompatibilidad y de laboratorios, gastos de intervenciones quirúrgicas, conservación de los órganos, costos incurridos en su distribución e importes posteriores relacionados con la extracción del órgano o material anatómico.

- Beneficios macroeconómicos en el área de la salud: desde el área de la inversión en salud, en el Documento de Trabajo SANCO C6 de la Comisión de las Comunidades Europeas al Parlamento Europeo y al Consejo sobre la Donación y el Trasplante de Órganos (2007), en el numeral 7.2 denominado "Repercusiones económicas", se hace una breve mención del costo-beneficio en los presupuestos nacionales con referencia expresa al impacto en los presupuestos sanitarios nacionales. Se señala allí que cerca del $3 \%$ se dedica a personas que esperan un trasplante y que la necesidad de normas de calidad y seguridad podrían encarecer el proceso o reducir los costos y facilitar el intercambio transfronterizo de órganos.

Como puede verse, el mercado de los órganos y tejidos no solo comporta un lado prohibido sino también uno permitido, dentro del cual se desarrolla una gran industria que aporta cifras significativas a las economías locales y a las empresas multinacionales.

Además, en algún momento terminan integrándose los mercados lícitos con los ilícitos en la fusión que implica la economía de los trasplantes, "[...] como ocurre desgraciadamente en la industria moderna, la producción continúa -incluso por medios ilícitos- mientras la necesidad exija y pague holgadamente el producto o satisfactor" (Martínez, 2002, p. 711).

Ahora bien, la industria del trasplante implica la intervención económica del Estado a través de múltiples medios como normas a todos los niveles (leyes, decretos, resoluciones), decisiones 
judiciales, controles administrativos a la importación y exportación, controles sanitarios, etc. Esto se debe básicamente a tres razones: primera, los Estados son los responsables de vigilar o mantener el equilibrio de los mercados para evitar abusos por parte de competidores más grandes frente a los pequeños y de sostener la diversidad de oferentes en el mercado nacional. Segunda, el Estado es garante del bienestar de los consumidores, que son ciudadanos, y a los cuales les debe garantizar productos y servicios idóneos que satisfagan sus necesidades, asegurando el equilibrio del mercado, el Estado salvaguarda el bienestar de los consumidores; $y$, por último, la salud es un tema de orden público, en donde el interés general y público prima sobre el individual.

Por lo anterior, los Estados asumen actitudes concretas frente al mercado de los órganos y tejidos humanos, evitando que el derecho a la creación de empresa se vea invadido de prácticas no deseadas como la instrumentalización del ser humano por parte de compañías no legales; pero además, protegen a los consumidores en cuanto procuran el control del movimiento de los componentes humanos, no en beneficio de unos pocos sino en favor del bienestar común, sin preferencias económicas ni barreras sociales; $y$, mantienen el orden público evitando que el secuestro, la trata de personas y las enfermedades contagiosas (como el VIH o las hepatitis) alteren el orden social.

\section{La exportación de componentes humanos}

Dentro del comercio actual es primordial tener presente los temas de la importación y exportación de bienes y servicios, situación que ha permitido -junto con los medios de información y las nuevas tecnologías-globalizar los mercados, haciendo del comercio una actividad sin fronteras continentales. Por ello, un asunto imposible de obviar en un trabajo sobre la incidencia del comercio de componentes humanos en el derecho privado es el de la exportación, por lo que la investigación sobre la materia conlleva la revisión de las normas que regulan la situación en algunos países latinoamericanos, para tener una radiografía general de la tendencia jurídica en la región.

La OMS, publicó el documento Principios rectores de la OMS sobre trasplante de células, tejidos y órganos humanos, aprobado en la $63^{\mathrm{a}}$ Asamblea Mundial de la Salud en mayo de 2010, y el principio rector 6 determina que "Deberán prohibirse así mismo los servicios de intermediación que entrañen el pago a esos individuos o a terceros" (OMS, 2010, p. 7). Pero el principio rector 10, hace un expreso reconocimiento a la exportación de productos humanos: "[...] es preciso instituir sistemas de garantía de la calidad que abarquen la trazabilidad y la vigilancia, y que registren las reacciones y eventos adversos, tanto a nivel nacional como en relación con los productos humanos exportados" (OMS, 2010, p. 9). Así se entenderá que la OMS admite que se exporten componentes humanos dentro del marco de la ausencia de ánimo de lucro.

Este aspecto de la exportación de componentes humanos tiene un relativo progreso normativo en los sistemas reglamentarios de algunos países latinoamericanos.

\section{Exportación en México}

La Ley General de Salud de 1983 presenta múltiples disposiciones sobre la salida de componentes humanos del territorio mexicano. Por ejemplo, declara en el artículo 317 que

Los órganos no podrán ser sacados del territorio nacional. Los permisos para que los tejidos y sus componentes, así como las células puedan salir del territorio nacional, se concederán siempre y cuando estén satisfechas las necesidades de ellos en el país, salvo casos de urgencia.

No obstante, hay una particularidad en este artículo, y es que fue reformado por el Congreso General de los Estados Unidos Mexicanos², por-

Reforma realizada por "Decreto por el que se reforman los artículos 198, 314, 317, 338 [y] 339; se adicionan 
que en el artículo de la versión anterior prohibía la salida de la nación de órganos, pero también de tejidos y células, los cuales no aparecen en esta nueva normativa; la nueva versión limita la salida de órganos pero permite condicionadamente el egreso de tejidos, sus componentes y células. Esta reforma fue propuesta en Dictamen de la Comisión de Salud, mirando en particular el tema de las células progenitoras o troncales. La sangre se considera tejido (art. 341, Ley General de Salud), por lo que se permite su exportación en los términos legales.

La prohibición de extraer del territorio nacional los componentes humanos se refuerza por la sanción penal. En específico, la ley mexicana destina los artículos 459, 460 y 461 a señalar que quien por cualquier medio pretenda sacar o efectivamente saque del territorio nacional sin permiso de la entidad competente sangre humana, derivados de la sangre, y en general órganos, tejidos y sus componentes, tanto de seres humanos vivos como de cadáveres, puede tener sanciones de multa y prisión entre uno y quince años, con pena de suspensión en el ejercicio de la profesión u oficio para los profesionales, técnicos o auxiliares de la salud que sean responsables.

La condición de estar cubiertas las necesidades nacionales antes de hacer remisiones al exterior, es una disposición que se encontrará de manera reiterada en las demás disposiciones sobre el tema.

\section{Exportación en Guatemala, Honduras y El Salvador}

El decreto 90-97 de 1997 del Código de Salud, expedido por el Congreso de la República de Guatemala, alude en concreto a la salida de sangre del país en el artículo 228 al legislar sobre los casos especiales que constituyen infracciones contra la rehabilitación de la salud, el numeral

los artículos 314, 315, 316, 321 Bis, 327 y 338 de la Ley General de Salud" del 20 de diciembre de 2012 y publicado en el Diario Oficial el 24 de enero de 2013. Este mismo artículo también había sido reformado por decreto del Congreso General del 28 de abril de 2000 , que se publicó en el Diario Oficial el 26 de mayo de 2000.
21 reza: "Suministrar sangre o sus derivados con destino al exterior del país, salvo las excepciones establecidas en la ley específica que regula la materia".

En esta misma orientación el Código de Salud, decreto 955 de 1988 expedido por la Asamblea Legislativa de la República de El Salvador, en el artículo 284 dispone como infracciones graves contra la salud, "14) La compra de sangre con fines lucrativos, la venta de la que hubiere sido donada o la práctica de la plasmaféresis, y la exportación de sangre, plasma o sus derivados".

De manera más amplia, el artículo $9^{\circ}$ del decreto 91-96 de 1996 de la República de Guatemala respecto a la disposición de órganos y tejidos, ordena que "queda terminantemente prohibida la venta y comercialización interna y exportación de cualquier órgano o tejido. Los infractores de esta disposición serán sancionados según lo establecido en el Código de Salud, sin detrimento de las sanciones penales que pudieren ampliarse".

El decreto 955 de 1988 de El Salvador, concretamente define en el artículo 128-M en la sección sobre trasplantes o tejidos que:

La entrada o salida de órganos o tejidos a El Salvador con fines terapéuticos, así como su movimiento en el interior del territorio nacional, solo podrá ser autorizada por el Ministerio de Salud Pública y Asistencia Social, previa asesoría del Consejo Nacional de Trasplante.

Por su parte, la República de Honduras presenta una redacción distinta frente al mismo tema; así se expresa en el artículo 22 del decreto 131, que se publicó en el Diario Oficial La Gaceta número 24029 de fecha 7 de junio de 1983, Ley de Trasplante y Extracción de Órganos y Tejidos Humanos:

Se promoverá la coordinación sin fines comerciales, entre este banco y los existentes en otros países, con el objeto de obtener el intercambio y rápida circulación de órganos 
y tejidos humanos para lograr así un máximo de seguridad en el proceso de histocompatibilidad del trasplante.

Como puede observarse, la redacción de este artículo respecto de los demás que se ubican desde la negación, la prohibición o la restricción, tiene dos características especiales: primera, se basa en el valor jurídico de la seguridad para el paciente; y segunda, no legisla desde la perspectiva de restricción sino de cooperación, situaciones que deben destacarse del legislador hondureño.

\section{Exportación en Colombia}

De entrada hay que decir que en Colombia, desde la ley 9/1979 se prohíbe la exportación de sangre, tal como lo define el artículo 545: "Se prohíbe la exportación de sangre o de sus fraccionados, salvo en los casos de excepción que establezca la presente ley". Posteriormente, en desarrollo de esta disposición, el decreto 1571/1993 en el artículo $8^{\circ}$ prohíbe la exportación total de sangre o de sus componentes.

Sin embargo, la norma no fija una prohibición absoluta, la ley permite que haya excepciones y el artículo $8^{\circ}$ del decreto en mención determina que:

[...] únicamente por razones de grave calamidad pública o atendiendo motivos de solidaridad internacional, dejando a salvo la atención de las necesidades nacionales, el Ministerio de Salud podrá autorizar la exportación, en forma ocasional, de sangre o sus componentes con fines exclusivamente terapéuticos y sin ánimo de lucro.

Entonces queda claro que en Colombia, la exportación de sangre está prohibida salvo por razones de solidaridad internacional, como en México. Y tampoco puede operar el ánimo de lucro, aun cuando la prohibición podría entenderse solo dentro del ámbito nacional y al involucrarse entidades o personas externas al país podría considerarse la posibilidad del lucro, incluso aunque fuera solo para las entidades de carácter gubernamental, pero la normatividad es coherente para lo interno y lo externo.

Lo anterior atendiendo las disposiciones sobre sangre. Respecto del resto de los tejidos, el decreto 2493/2004 dispone en el artículo 37 sobre la salida de tejidos o médula ósea fuera del territorio nacional que:

[...] solo podrá efectuarse en calidad de donación con fines de trasplante o implante, atendiendo motivos de solidaridad humana y sin ánimo de lucro, previa autorización expedida por el Instituto Nacional de Vigilancia de Medicamentos y Alimentos, Invima. La salida solo podrá realizarse a través de los Bancos de Tejidos o Bancos de Médula Ósea.

Incluso la salida de componentes humanos entendidos como muestras comerciales está prohibida desde el mismo Estatuto Aduanero, decreto 2685/1999, que en el artículo 320 señala qué productos no pueden exportarse desde la modalidad de muestras sin valor, entre los que se destacan el café, las esmeraldas, el oro, los estupefacientes, el plasma y los órganos humanos.

\section{Exportación en Bolivia}

Sobre la exportación de órganos indica el artículo $18^{\circ}$ de la ley 1716/1996 de Bolivia, Ley de Donación y Trasplantes de Órganos, Células y Tejidos: "Se prohíbe la exportación de órganos, tejidos y células salvo que se trate de intercambios con fines benéficos debiendo precautelar siempre las necesidades nacionales no permitiéndose remuneración alguna por estos actos".

El 21 de junio de 1997 se promulgó el decreto supremo 24671 que reglamenta la organización, funcionamiento y procedimientos de los servicios de salud dedicados a la ablación y trasplante de órganos, células y tejidos, pero en dicho decreto no se hizo alusión alguna a la exportación de componentes humanos. Aunque la ley 1687 del 26 de marzo de 1996, Ley de la Medicina Transfusional y Bancos de Sangre, establece en el artículo 4 que "Se prohíbe la exportación de 
sangre humana, sus componentes y derivados, salvo circunstancias de emergencia internacional, en cuyo caso, se requerirá autorización expresa de la Secretaría Nacional de Salud".

\section{Exportación en Chile}

Los chilenos cuentan con la ley 19.451/1996, modificada por las leyes 20.413/2010 y 20.673/2013, que en el artículo 14 prescribe:

[...] la importación y la exportación de órganos con fines de trasplante podrán efectuarse solamente a título gratuito, por los hospitales y clínicas a que se refiere el artículo $2^{\circ}$ y por aquellas entidades que, dada su vinculación con las materias reguladas por esta ley, sean autorizadas para ello por el Ministerio de Salud.

La ley 19.451 ordena que el artículo precedente no sea aplicable a las donaciones de sangre. Aunque su reglamento es mucho más preciso. Así, el decreto 656 del 5 de julio de 1996, dispone un título para la importación y exportación de órganos a título gratuito, haciendo control sobre las entidades (hospitales y clínicas) que pueden internar "órganos provenientes de donantes ubicados fuera del territorio nacional" y que "podrán también internar al país órganos, otras entidades vinculadas a las materias de que trata este reglamento, siempre que cuenten con una autorización especial, extendida, por el Ministerio de Salud para este efecto" (art. 26). Deja claridad que la internación y la donación deben realizarse siempre a título gratuito. Y el artículo 27 manifiesta que:

Las entidades mencionadas en el artículo anterior podrán proceder a la exportación de órganos en aquellos casos en que no existan receptores disponibles, según informe que deberá otorgar el Instituto de Salud Pública, conforme a las prioridades que se establecen en el artículo 30.

\section{Exportación en Costa Rica}

En Costa Rica la Ley General de Salud, 5395/1973, ordena en el artículo 94 que: "Queda prohibido a los establecimientos privados la exportación de sangre humana, plasma y sus derivados, salvo en casos de emergencia calificados, a juicio del Ministerio". Cuando hace referencia la norma a los establecimientos privados apunta a los bancos de sangre, los cuales pueden ser instalados y operados por cualquier persona natural o jurídica.

El caso de Costa Rica presenta una variable interesante en el tema de la exportación de componentes anatómicos para tratar el asunto de los componentes humanos como mercancía de carácter internacional, porque a raíz del Tratado de Libre Comercio (TLC) con Estados Unidos, surgió una crítica por parte de reconocidos médicos costarricenses y reproducida ampliamente por los medios de comunicación, en el sentido que el TLC motiva el tráfico de órganos y tejidos humanos, ya que se encuentran tipificados como mercancías con arancel cero. Y efectivamente, el TLC (ítem número 300019010 del anexo 3.3) otorga un arancel cero al movimiento transnacional de huesos, órganos y tejidos humanos para injertos o trasplantes. De hecho, ya preocupa el hecho de llamar "mercancía" a los componentes humanos. Otra crítica que se le hace a la posibilidad de importar componentes humanos libres de impuestos, es que dadas las restricciones existentes en los Estados Unidos para la investigación con células madre y embriones, Costa Rica podría convertirse, en virtud del TLC, en un gran depósito o enorme banco de microorganismos, embriones y/o células madre, para los intereses estadounidenses.

El Gobierno, a través del ministro de Comercio Exterior, y otras personalidades respondieron señalando que el TLC había sido declarado constitucional por la Sala Constitucional. Que desde 1985 se eliminaron los impuestos para huesos y córneas que se han importado aun sin TLC para fines terapéuticos; que Costa Rica no exporta ningún componente humano o sus derivados. Que el arancel cero para huesos, órganos y tejidos humanos tiene un carácter humanitario para salvar vidas y obedece a la importación de estos componentes para emergencias médicas tal como se hace en la actualidad. Además, que 
la referencia a los órganos humanos como mercancía no se sujeta a otra cosa que al uso de un lenguaje técnico empleado en el comercio y que en ningún momento busca estimular el tráfico de órganos. Que la clasificación y codificación arancelaria de los órganos y tejidos es común, internacional y se encuentra incluso en las listas de la Organización Mundial del Comercio, por lo que no es algo nuevo ni extraño y que tal como lo dijo la Sala Constitucional, la inclusión de estos componentes en los listados arancelarios no implica su libre comercialización por encima de la legislación nacional (Ruiz, 2007).

Ante lo crucial de la materia, se consultó directamente la sentencia constitucional, en la cual se evidencia que en ninguna parte esta hace mención de los órganos, tejidos o huesos humanos. No obstante, sí hace un análisis frente a las armas y municiones, por su parte el Ministro de Comercio Exterior hace una lectura aplicada al tema de los componentes humanos. El fragmento de la sentencia de la Sala Constitucional de la Corte Suprema de Justicia de Costa Rica, sentencia res. 2007-09469, exp.: 07-005632-0007-CO y 07-007153-0007-CO (2007) es el siguiente, que debe leerse en clave de los órganos y tejidos humanos:

Surge la duda sobre los alcances que tiene la lista de eliminación de aranceles en el ordenamiento jurídico costarricense, y si nuestro país comprometió de alguna forma la seguridad nacional únicamente con la suscripción de dicha lista. En primer lugar, debe indicarse que la lista contenida en el apartado de Desgravación Arancelaria del Tratado de Libre Comercio, es una lista uniforme de productos que es estándar a nivel internacional, según el Sistema Armonizado de Clasificación y Codificación de Mercancías acordado en la Organización Mundial de Aduanas (artículo 2.1 del Tratado), el cual agrupa los rubros de productos en noventa y seis capítulos, mil doscientos cuarenta y un partidas y más de cinco mil subpartidas. La idea de dicha lista, es incluir todos los productos imaginables y constituirse en una nomenclatura internacional multipropósito de mercancías, para lo cual incluso se hacen actualizaciones si se estima necesario incluir alguna otra mercancía (al respecto, puede consultarse la página web de la $\mathrm{OMC}$ ). Sin embargo, en el marco de las negociaciones comerciales, eso no significa que las listas en cuestión por sí mismas obliguen al libre comercio de esas mercancías por encima de la legislación nacional, si ello no es previsto expresamente en el acuerdo que se está negociando. Y basta poner un ejemplo extremo como el de la cocaína y las hojas de coca (partidas 29399100 y 12113000 ) para indicar que a pesar de encontrarse en la lista de desgravación arancelaria de Costa Rica, no significa que nuestro país tiene que permitir la libre comercialización de dichos productos, lo cual evidentemente no aceptarían países que forman parte del Tratado y que se han dedicado a combatir este tipo de drogas. De ahí que a pesar de que el Tratado de Libre Comercio asigna la eliminación de aranceles a todos los productos de la lista (incluyendo el armamento citado), ello no implica que nuestro país no pueda invocar su legislación interna para restringir el comercio de los mismos.

Los argumentos del Gobierno son jurídicamente coherentes, además de que tienen el respaldo de la Sala Constitucional de la Corte Suprema de Justicia con una clara razonabilidad. Empero, la discusión, aunque solo se encontró en Costa Rica, es pertinente en cuanto facilita la reflexión ética y jurídica, y el análisis sobre los posibles abusos que el mercado internacional puede tener sobre los países latinoamericanos; también despierta una conciencia general sobre las cosas públicas y el interés general.

\section{Exportación en Perú}

En Perú la ley 28189/2004 en el artículo $15^{\circ}$ exige, en general, que para el ingreso o salida de órganos y/o tejidos desde y hacia el territorio nacional se requiere autorización previa del Ministerio de Salud, que se haga a través de una 
organización legalmente reconocida en el país de origen o destino, y demandas éticas y sanitarias.

Aunque el decreto supremo 014-2005-SA, Reglamento de la Ley General de Donación y Trasplante de Órganos y/o Tejidos Humanos, destina un título con cinco artículos al "Traslado de órganos y tejidos a nivel internacional", expone que el ingreso y salida del territorio nacional de órganos y/o tejidos, así como de células madre y/o progenitores hematopoyéticos, es del Ministerio de Salud en coordinación con la Organización Nacional de Donación y Trasplante (ONDT) y la Superintendencia de Aduanas (arts. $49^{\circ}, 52^{\circ}$ y $53^{\circ}$ ); y que se promoverán convenios con organizaciones internacionales de trasplantes para la cooperación, intercambio y ayuda mutua para el desplazamiento de órganos, células madre y/o progenitores hematopoyéticos solo con fines de trasplante (arts. $50^{\circ}$ y $53^{\circ}$ ); pero la condición de salida es que no exista receptor adecuado en el país (art. 51\%).

\section{Exportación en Argentina}

En la República Argentina opera la ley 24.193, sancionada el 24 de marzo de 1993, sobre trasplantes de órganos y materiales anatómicos, en la cual no se hace una mención expresa respecto de la permisión de la exportación de componentes humanos, pero lo reconoce de forma indirecta en el artículo 44, cuando señala en el literal $\mathrm{m}$ ) dentro de las funciones del Instituto Nacional Central Único Coordinador de Ablación e Implante (Incucai) "Coordinar la distribución de órganos a nivel nacional, así como también la recepción y envío de los mismos a nivel internacional". De este modo queda avalada la importación y exportación de órganos, aunque el legislador argentino al parecer trató de evadir estos términos posiblemente por la connotación comercial que conlleva una discusión como la planteada en Costa Rica.

No obstante, la Ley de Sangre, ley 22.990/1983, tiene un capítulo titulado "De la importación y exportación de la sangre humana, sus componentes, derivados y elementos de diagnóstico" donde se usan los términos de manera clara. Por ejemplo, en el artículo 74 se dispone que "La sangre humana, sus componentes y derivados, solo serán utilizados en territorio nacional, quedando prohibida su exportación, con excepción de los casos en que por razones de solidaridad así lo autorice expresamente el Poder Ejecutivo nacional". Y en cuanto a la importación de sangre humana, componentes y derivados decreta que solo se puedan realizar cuando haya autorización expresa del Poder Ejecutivo nacional únicamente en los casos de necesidad o escasez debidamente comprobada (art. 75).

Al igual que la normativa peruana, el artículo 76 de la Ley de Sangre argentina indica la responsabilidad de la autoridad aduanera en lo que se relaciona con la importación y exportación de sangre y sus derivados.

De manera particular, el artículo 77 admite la importación para su posterior exportación: "La importación transitoria de sangre humana, componentes y derivados a título de materia prima para su industrialización y reexportación posterior podrá ser autorizada por el Poder Ejecutivo nacional conforme las modalidades que establezca la reglamentación". Aunque no señala el destino que se le brindaría o la intención de dicho proceso de industrialización, podría suponerse que se entiende desde la premisa establecida en el artículo 4 de la misma ley cuando ordena:

Prohíbese la intermediación comercial y el lucro en la obtención, clasificación, preparación, fraccionamiento, producción, almacenamiento, conservación, distribución, suministro, transporte, actos transfusionales, importación y exportación y toda forma de aprovechamiento de la sangre humana, sus componentes y derivados, con las excepciones que se contemplan en la presente ley.

\section{CONCLUSIONES}

La investigación arroja las siguientes conclusiones en cuanto a la exportación de componentes humanos en los países latinoamericanos en estudio: No todos los países hacen mención expresa de la importación o exportación de componentes 
humanos en sus respectivas normativas. Esto quizá obedezca a la baja cultura de donación en las naciones, lo que podría llevar a no observar la necesidad de ello o la simple consideración del respectivo legislador de no tolerar la salida de estos bienes dada su naturaleza e importancia para la salud pública.

Además, todos los aspectos de la importación y la exportación de órganos y demás componentes humanos están enmarcados dentro de la prohibición general del ánimo de lucro en estas transacciones.

De la revisión normativa de los países en análisis, aunque no hay un cuerpo de leyes unificado sí se evidencian muchos elementos comunes. Parten todos de la premisa básica y universal de la prohibición a la comercialización de los órganos humanos y la insistencia sobre la donación con ánimo altruista.

Los países que se trataron en el artículo permiten la exportación de órganos y/o tejido, salvo México que prohíbe la exportación de órganos pero no la de tejidos y células. Y sobre las células, las refieren expresamente México, Argentina, Perú y Bolivia. Pero también, entiendo la sangre como tejido, México, Guatemala, Colombia, Bolivia, Costa Rica y Argentina aceptan su exportación. Colombia en particular admite la entrada o salida de sangre con fines terapéuticos y El Salvador conserva igual requisito para órganos y tejidos.

Tanto México, como Chile y Perú son taxativos en manifestar que la salida del país de componentes humanos solo puede ser posible si las necesidades internas están satisfechas, si no hay receptores nacionales disponibles (Chile) o si no existe receptor adecuado en el país (Perú), lo que confirma el principio de preferencia nacional. No obstante, en relación con el también principio de solidaridad, las legislaciones de México, Colombia, Bolivia y Costa Rica permiten la exportación de órganos con preferencia sobre los nacionales, en casos de urgencia, sin definir en las mismas normas qué puede considerarse emergencia.
Una constante en todas las normativas que autorizan la salida de componentes humanos de sus respectivos países es la exigencia de la autorización previa por parte de una entidad nacional, sea el ministerio correspondiente o la organización encargada de las donaciones y trasplantes de órganos; con la característica de que debe ser una autorización a priori, regirse por lo que indica el párrafo anterior en lo que atañe a la satisfacción de necesidades internas de manera prioritaria y que su control se centre en el ámbito nacional. Ello facilitaría un mayor control sobre las necesidades propias en el país y sobre el comercio ilegal de los órganos y tejidos. En el caso de España opera de igual modo para la importación y exportación de células y tejidos, concentrado en el Ministerio de Sanidad previo informe de la Organización Nacional de Trasplantes (Abad et al, 2010).

Por otra parte, en las normas de Colombia, Perú y Argentina se hace mención concreta a las funciones de las respectivas oficinas de aduanas, situación a todas luces obvia tanto desde lo jurídico como desde lo institucional, toda vez que son esas entidades las responsables de la inspección y vigilancia de toda la mercancía que entra o sale del país, dentro de la cual se pueden hallar componentes humanos. Por ello Colombia es enfática en aclarar que los componentes humanos no pueden salir del país desde la figura de muestras comerciales (decreto 2685/1999, art. 320) y apunta a la colaboración armónica entre las instituciones.

Además, las normas de Honduras, Colombia y Perú enmarcan la exportación de componentes humanos en la seguridad del paciente y la existencia de acuerdos de cooperación o convenios con las organizaciones respectivas de otros países, limitando así las entidades que pueden disponer de un órgano o tejido en el exterior y reduciendo el margen de maniobra por parte de terceros interesados en exportar o importar componentes humanos con ánimo de lucro.

La discusión sobre la exportación e importación de componentes humanos no es agresiva en la actualidad, pero tampoco pacífica del todo por los elementos de ilegalidad que se mueven alrededor, 
como el turismo de órganos, pero igualmente por los hechos legales, como la preferencia nacional antes que exportar en un mundo de fronteras abiertas o la obligación de atender extranjeros que solo se desplazan a un país latinoamericano para ser incluidos en las listas con el fin de ser beneficiarios de un órgano, desplazando en necesidades a un nacional.

De hecho, en 2010, la Comisión de Estudios Jurídicos del Parlamento Europeo, en un proyecto de opinión dirigido a la Comisión de Medio Ambiente, Salud Pública y Seguridad Alimentaria,

[...] pide a los Estados miembros que consideren la eliminación de las restricciones al transporte transfronterizo de órganos; considera que un sistema flexible entre Estados miembros para el trasplante, el intercambio, la importación y la exportación de órganos podría salvar muchas vidas, al permitir a más personas encontrar donantes adecuados (p.3).

No obstante, la anterior propuesta encuentra serias oposiciones teniendo en cuenta el interés de entidades y particulares por hacer de la necesidad de órganos y tejidos un negocio; y el abuso que podría presentar para los países en vías de desarrollo abrir sus fronteras a naciones desarrolladas para un intercambio libre (aunque no precisamente lucrativo), donde la capacidad adquisitiva de los países con economías más fuertes podría terminar volviéndose en contra de las necesidades de los nacionales de países con economías débiles.

\section{REFERENCIAS}

Abad, J. M. et al. (2010). Normas básicas de bioderecho. Madrid: Dykynson, Uned, Universidad Pontificia Comillas.

Argentina. (1983, 28 de noviembre). Ley 22.990. Ley de Sangre.

Argentina. (1993, 24 de marzo). Ley 24.193. Trasplante de Órganos y Materiales Anatómicos.
Baquero, A. \& Alberú, J. (2011). Desafíos éticos en la práctica de trasplantes en América Latina: documento de Aguascalientes. Revista Nefrología, $31,3,275-285$.

Bolivia. (1996, 26 de marzo). Ley 1687. Ley de la Medicina Transfusional y Bancos de Sangre.

Bolivia. (1996, 5 de noviembre). Ley 1716. Ley de Donación y Trasplante de Órganos, Células y Tejidos.

Bolivia. (1997, 21 de junio). Decreto supremo 24671, que reglamenta la Ley de Donación y Trasplante de Órganos, Células y Tejidos del Estado Plurinacional de Bolivia.

Brena, I. (2002). Reflexiones jurídicas en torno a los sujetos que intervienen en un trasplante de órganos. Boletín Mexicano de Derecho Comparado, XXXV, 105, 797-816.

Cantú-Quintanilla, G. et al. (2010). Acceso a trasplante renal de donante fallecido en pacientes pediátricos de América Latina y el Caribe. Persona y Bioética, 14, 2, 151-162.

Capella, F. (2001). Trasplantes, eficiencia y altruismo. Recuperado de http://www.juandemariana. org/articulo/64/trasplantes/eficiencia/altruismo/

Chile. (1996, 29 de marzo). Ley 19.451. Establece normas sobre trasplante y donación de órganos.

Chile. (1996, 5 de julio). Decreto 656. Aprueba reglamento de la ley 19.451, que establece normas sobre trasplante y donación de órganos.

Chile. (2013, 29 de mayo). Ley 20673. Modifica la ley 19.451 respecto a la determinación de quiénes pueden ser considerados donantes de órganos.

Colombia. (1979, 24 de enero). Ley 9. Por la cual se dictan medidas sanitarias.

Colombia. (1993, 12 de agosto). Decreto 1571. Por el cual se reglamenta parcialmente el Título 
IX de la ley 09/1979, en cuanto a funcionamiento de establecimientos dedicados a la extracción, procesamiento, conservación y transporte de sangre total o de sus hemoderivados, se crean la Red Nacional de Bancos de Sangre y el Consejo Nacional de Bancos de Sangre y se dictan otras disposiciones sobre la materia.

Colombia. (1999, 28 de diciembre). Decreto 2685. Por el cual se modifica la Legislación Aduanera.

Colombia. (2004, 4 de agosto). Decreto 2493. Por el cual se reglamentan parcialmente las leyes 9a/1979 y 73/1988, en relación con los componentes anatómicos.

Comisión de Estudios Jurídicos del Parlamento Europeo (2010). Informe sobre la Comunicación de la Comisión titulada «Plan de acción sobre donación y trasplante de órganos (2009-2015): cooperación reforzada entre los Estados miembros» $<1$ Titre $><$ DocRef $>(2009 / 2104($ INI) $)$. Recuperado de http://www.europarl.europa.eu/sides/getDoc. do?pubRef $=-/ / E P / / N O N S G M L+R E P O R T+A 7-$ 2010-0103+0+DOC+WORD+V0//ES

Comisión de las Comunidades Europeas. (2007). Comunicación de la Comisión al Parlamento Europeo y al Consejo sobre la Donación y el Trasplante de Órganos. Opciones estratégicas a nivel de la U. E. Recuperado de http://eur-lex. europa.eu/legal-content/ES/ALL/;jsessionid $=Y$ Gf8TRGNvhdRfljJMRGcFW35vFRfbNPbYmy 3pmLJDTKf6y6hx2df!-1614442047?uri=CEL EX:52007SC0705

Corte Constitucional de Colombia. (1994). Sentencia T-162/1994. M. P. Eduardo Cifuentes Muñoz.

Corte Suprema de Justicia de Costa Rica. (2007). Sentencia res. 2007-09469, exp.: 07-0056320007-CO y 07-007153-0007-CO.

Díaz-Ambrona, M. D., Serrano, A., Fuertes, J. C. \& Hernández, P. (2007). Introducción a la medicina legal. Madrid: Ediciones Díaz de Santos.
García, G. A. (2011). La publicidad sobre órganos y componentes humanos en Latinoamérica. Opinión Jurídica, 10, 19, 85-98.

García, G. A. (2012). El derecho latinoamericano y español frente a la comercialización de componentes humanos desde el derecho comercial. Pensamiento Jurídico, 33, 165-194.

Gracia, D. (1996). Historia del trasplante de órganos. En: Gafo, J. (ed.). Trasplantes de órganos: problemas técnicos, éticos y legales (13-32). Madrid: Universidad Pontificia Comillas.

Guerra, Y. \& Márquez, A. (2011). Bioética, trasplante de órganos y derecho penal en Colombia. Revista Prolegómenos. Derechos y Valores, XIV, 45-59.

El Salvador. (1998, 28 de abril). Decreto 955. Código de Salud.

El Universal Compañía Periodística Nacional. (2009). Recompensa a médicos que consigan órganos. Recuperado de http://www.eluniversal. com.mx/nacion/165280.html

Guatemala. (1997, 2 de octubre). Decreto 90-97. Código de Salud.

Guatemala (1996, 31 de octubre) Decreto 91-96. Ley para la Disposición de Órganos y Tejidos Humanos.

Honduras. (1983, 11 de noviembre). Decreto 131. Ley de Trasplante y Extracción de Órganos y Tejidos Humanos.

López-Navidad, A., Kulisevsky, J. \& Caballero, F. (1997). El donante de órganos y tejidos: evaluación y manejo. Barcelona: Springer-Verlag Ibérica.

Manterola, D. C. Manterola Delgado, C.; Silva Aldunace, J.; Horta X., J.; López A., A.; Stephens K., C.; Watkins C., R. y Castillo M., L (1997). Perfil clínico de los potenciales donantes del Hospital Regional de Temuco. Revista Chilena de Cirugía, 49, 2, 180-187. 
Martínez, J. (2002). La figura del contrato en los trasplantes de órganos humanos. México D. F.: Porrúa.

México. (1983, 26 de diciembre). Ley General de Salud.

México. (2000, 28 de abril). Decreto modificatorio de la Ley de Salud.

México. (2012, 20 de diciembre). Decreto por el que se reforman los artículos 198, 314, 317, 338 y 339; se adicionan los artículos 314, 315, 316, 321 Bis, 327 y 338 de la Ley General de Salud.

Ministerio de la Protección Social de Colombia. (2006). Conceptos del Ministerio de la Protección Social en materia de salud. Bogotá: Ministerio de la Protección Social.

Organización Mundial de la Salud. (2010). Principios rectores de la OMS sobre trasplante de células, tejidos y órganos humanos. Recuperado de http://www.who.int/transplantation/Guiding_ PrinciplesTransplantation_WHA63.22sp.pdf

Organización Panamericana de la Salud. (2013). Legislación sobre donación y trasplante de órganos, tejidos y células. Compilación y análisis comparado. Recuperado de http://www.paho.org/ hq/index.php?option $=$ com_docman\&task $=$ doc view\&gid $=21392 \&$ Itemid

Parlamento Europeo. Comisión de Asuntos Jurídicos. (2009). Proyecto de opinión de la Comisión de Asuntos Jurídicos para la Comisión de Medio Ambiente, Salud Pública y Seguridad Alimentaria sobre la Comunicación de la Comisión "Plan de acción sobre donación y trasplante de órganos (2009-2015): cooperación reforzada entre los Estados miembros". Recuperado de http:// www.europarl.europa.eu/meetdocs/2009_2014/ documents/juri/pa/797/797778/797778e-s.pdf
Perú. (2004, 16 de marzo). Ley 28189. Ley General de Donación y Trasplante de Órganos y/o Tejidos Humanos.

Perú. (2005, 23 de mayo). Decreto supremo 014-2005-SA. Reglamento de la Ley General de Donación y Trasplante de Órganos y/o Tejidos Humanos.

Puerto Rico. (2002, 25 de diciembre). Ley 296. Ley de Donaciones Anatómicas de Puerto Rico, enmendada por la ley $26 / 2011$, ley $85 / 2012$ y 210/2012.

Ruiz, M. V. (2007). Aclaración sobre el TLC y los órganos y tejidos humanos y el Tratado de Budapest. Recuperado de https://www.google. com.co/search?q=organos + tejidos + TLC+site \%3A.comex.go.cr\&rlz=1C1CHNY_esCO367C O367\&oq $=$ organos + tejidos $+\mathrm{TLC}+$ site $\% 3 \mathrm{~A}$. comex.go.cr\&aqs $=$ chrome. $.69 \mathrm{i} 57.2561 \mathrm{j} 0 \mathrm{j} 7 \& \mathrm{~s}$ ourceid $=$ chrome\&es_sm $=122 \& i e=U T F-8$

Sánchez, E. (2005). El trasplante de órganos en la legislación española: delimitación de problemas y argumentación ética. En: Ruiz, A. Bioética y derechos humanos: implicaciones sociales y jurídicas (345-360). Sevilla: Universidad de Sevilla.

Sodi, M. de L. (2003). La experiencia de donar: estudio antropológico sobre la donación de órganos. México D. F.: Plaza y Valdés, Instituto Nacional de Antropología e Historia.

Torres, S. \& Gutiérrez, J. P. (2009). Mercado farmacéutico en México: tamaño, valor y concentración. Revista Panamericana de Salud Pública, 26, 1, 46-50.

Venezuela. (1992, 3 de diciembre). Ley sobre Trasplante de Órganos. 